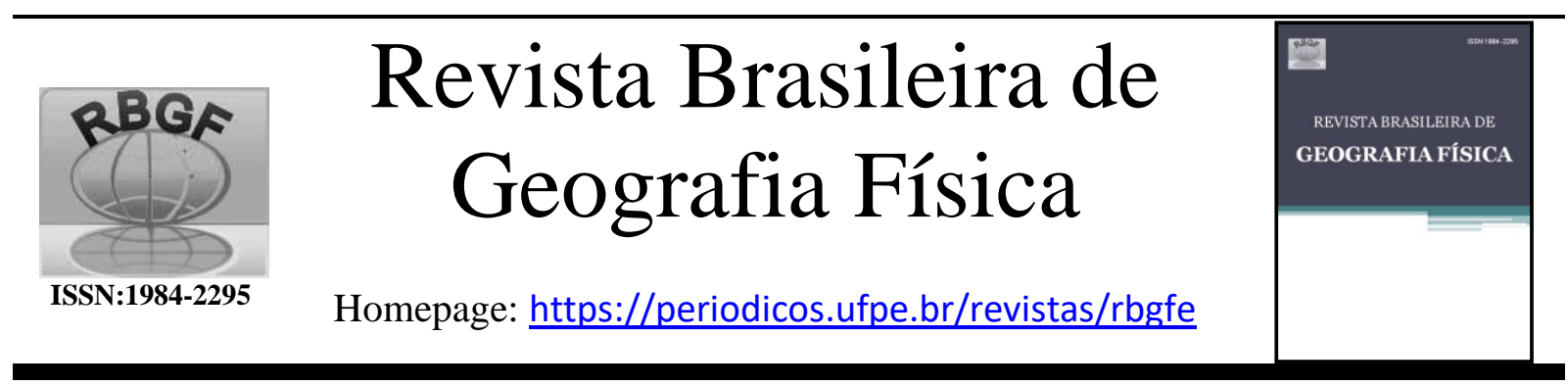

\title{
Índice de anomalia de chuvas da Microrregião do Cariri Ocidental Paraibano
}

\author{
Renata Richelle Santos Diniz ${ }^{1}$, Maria Leide Silva Alencar ${ }^{2}$, Shayenny Alves de Medeiros ${ }^{3}$, Hugo Orlando Carvallo \\ Guerra $^{4}$, Julio Cesar Rodrigues de Sales 5
}

\begin{abstract}
${ }^{1}$ Engenheira de Biossistemas, Mestranda em Engenharia Agrícola, Universidade Federal de Campina Grande Campus de Campina Grande- PB, Rua: Aprígio Veloso, 882, Bairro Universitário, Bodocongó, CEP: 58429-900. renata_richelle@ hotmail.com (autor correspondente). ${ }^{2}$ Dra., Engenheira Agrícola, Professora adjunta, Unidade Acadêmica de tecnologia de Desenvolvimento, Universidade Federal de Campina Grande, Rua Luiz Grande, s/n, CEP 58540-000, Sumé, Paraíba, (83) 3353- 1873. mlsalencar@yahoo.com.br. ${ }^{3}$ Engenheira de Biossistemas, Mestranda em Engenharia Agrícola, Universidade Federal de Campina Grande Campus de Campina Grande- PB, Rua: Aprígio Veloso, 882, Bairro Universitário, Bodocongó, CEP: 58429900. shayalvesmedeiros@ gmail.com. ${ }^{4}$ Professor Titular, Unidade Acadêmica de Engenharia Agrícola, Universidade Federal de Campina Grande, Rua: Aprígio Veloso, 882, Bairro Universitário, Bodocongó, CEP: 58429-900, Campina Grande, Paraíba. hugo_carvallo@ hotmail.com. ${ }^{5}$ Engenheiro de Biossistemas, Mestrando em Engenharia Agrícola, Universidade Federal de Campina Grande Campus de Campina Grande- PB, Rua: Aprígio Veloso, 882, Bairro Universitário, Bodocongó, CEP: 58429-900. julioo5rodrigues@ outlook.com.
\end{abstract}

Artigo recebido em 17/01/2020 e aceito em 04/11/2020

\section{R E S U M O}

A região semiárida do Brasil tem como particularidade a grande irregularidade na precipitação, comportamento esse decorrente de um conjunto de fatores, desde características geográficas, como também fenômenos atmosféricos. Por essa razão, o presente trabalho teve como objetivo analisar a variabilidade climática da microrregião do Cariri Ocidental Paraibano composto por 17 munícipios, através da utilização do Índice de Anomalia de Chuva (IAC) e correlacionar a classificação desse índice com a ocorrência, intensidade e influência do Fenômeno El Niño. Foram utilizados dados pluviométricos de um período de 21 anos (1999-2019) disponibilizados pela AESA (Agência Executiva de Gestão das Águas do Estado da Paraíba) aplicados no cálculo do IAC que nos permitiu identificar a intensidade e duração dos períodos secos e úmidos da série, foram empregados também dados do El Niño, concedidos pelo Centro de Previsão de Tempo e Estudos Climáticos (CPTEC) e Instituto de Pesquisas Espaciais (INPE). As incidências de anomalias (negativas e positivas) de precipitação foram analisadas mensalmente e anualmente. A climatologia temporal da precipitação da microrregião do Cariri Ocidental paraibano mostrou que seu período chuvoso inicia-se no mês de janeiro a maio, em contrapartida o período seco ocorre entre os meses de junho a dezembro, sendo setembro tido como o mês mais seco. O mês de agosto contabilizou o maior número de vezes no qual foi classificado como mês úmido (17 vezes), e julho o mês que foi classificado como mais repetidamente seco (9 vezes). Ainda utilizando o cálculo do IAC, foi possível determinar a quantidade de anos secos (10 anos) e úmidos (11 anos), ressaltando que o ano de 2012 foi o único classificado como ano de seca extremamente alta, onde o mesmo foi classificado como um ano de El Nino de intensidade forte. Assim conclui-se a importância da metodologia empegada para o acompanhamento interanual da precipitação pluviométrica da região do Cariri Ocidental paraibano vindo a tornar esses dados obtidos extremamente úteis para uma melhor compreensão da interação do fenômeno atmosférico El Niño e o regime de chuvas da região semiárida.

Palavras- chave: IAC, Período Seco, Período Chuvoso, semiárido, climatologia.

\section{Rain anomaly index of the Cariri Western Paraibano Microregion}

\section{A B S T R A C T}

The semi-arid region of Brazil is characterized by the great irregularity in precipitation, a behavior that results from a set of factors, from geographical characteristics, as well as atmospheric phenomena. For this reason, the present work aimed to analyze the climatic variability of the micro region of Cariri Oeste Paraibano composed of 17 municipalities, using the Rain Anomaly Index (IAC) and correlate the classification of this index with the occurrence, intensity and influence of the El Niño Phenomenon. Rainfall data from a period of 21 years (1999-2019) made available by AESA (Executive Water Management Agency of the State of Paraíba) was used in the calculation of the IAC, which allowed us to identify the intensity and duration of the dry and wet periods of the series, data from El Niño, granted by the Center for Weather Forecasting and Climate Studies (CPTEC) and the Institute for Space Research (INPE), were also used. The incidence of 
precipitation anomalies (negative and positive) were analyzed monthly and annually. The temporal climatology of precipitation in the Cariri Western Paraiba micro-region showed that its rainy period starts in the month of January to May, in contrast the dry period occurs between the months of June to December, with September being the driest month. The month of August had the highest number of times in which it was classified as a wet month (17 times), and July the month that was classified as the most repeatedly dry ( 9 times). Still using the IAC calculation, it was possible to determine the number of dry (10 years) and wet (11 years) years, emphasizing that 2012 was the only year classified as an extremely high drought year, where it was classified as a El Nino year of strong intensity. Thus, we conclude the importance of the methodology used for interannual monitoring of rainfall in the region of Western Cariri in Paraíba, making these data extremely useful for a better understanding of the interaction of the atmospheric phenomenon El Niño and the rain regime of the semiarid region.

Keywords: IAC, Dry Period, Rainy Period, semiarid, climatology.

\section{Introdução}

A água, um bem finito e cada vez mais escasso que está enfrentando problemas de quantidade e de qualidade, não é somente um elemento imprescindível à vida, mas também fator condicionante do desenvolvimento econômico e do bem estar social (Diniz, 2018).

Segundo Bezerra (2016), os fatores de ordem climática condicionada a fatores ambientais provocados pela falta ou escassez de chuva que contribuem para a estiagem no semiárido, levando assim, a semiaridez climática ou incidência das secas.

Ressalta-se que a sequência de dias secos ou chuvosos e até mesmo a quantidade total de chuvas durante $\mathrm{o}$ ano nas regiões semiáridas sofre influência importante de sistemas atmosféricos resultantes do padrão termodinâmico dos oceanos Atlântico e Pacífico, entre os quais podem- se destacar a ZCIT, (oceano Atlântico) e El Niño e La Niña, estes dois últimos oriundos oceano Pacífico (Nóbrega et al.,2016).

O impacto causado pelo fenômeno El Niño, dependendo da sua intensidade pode resultar em secas severas, interferindo de forma significativa nas atividades econômicas nas regiões Norte e Nordeste do Brasil (Sousa et al., 2015).

As chuvas irregulares e más distribuídas é uma das características naturais do clima semiárido, e sempre ele estará sujeito a secas periodicamente. Esta problemática está associada a três fenômenos: à temperatura da água do oceano atlântico, ao "El Niño", pelo aquecimento das águas do oceano pacífico e à baixa umidade atmosférica. Assim, para a população dessas áreas conviverem melhor nessas condições faz-se necessário à adoção de tecnologias de captação da água da chuva para usá-las tanto nos veranicos que ocorrem no período chuvoso como após este período (Santos e Alencar, 2015).

A Paraíba como outros estados da região semiárida, essa característica climática marcante, as irregularidades, tanto espacial quanto temporal do seu regime de chuvas (Francisco et al., 2015).
Segundo Da Silva (2009), com o emprego de índices climáticos, exemplo o IAC, pode-se desenvolver um sistema de acompanhamento das características dos períodos secos ou chuvosos, com informações anuais, sazonais ou mensais.

Os índices de seca fornecem representações espaciais e temporais das secas e, portanto, colocam as condições atuais em perspectiva histórica. Um destes índices é o Rainfall Anomaly Index (RAI) ou Índice de Anomalia de Chuva (IAC) desenvolvido por Rooy (1965). Este índice tem como principal característica, necessitar apenas de dados de precipitação para ser calculado, e visa tornar o desvio da precipitação em relação à condição normal de diversas regiões passíveis de comparação (Gross e Cassol, 2015).

Alves e Araújo (2015) utilizaram como determinação da influência da variabilidade espaço- temporal das chuvas, o IAC, para analisar a climatologia da bacia do rio Camaratuba- $\mathrm{PB}$, no qual utilizaram projeções de menos $20 \%$ e mais de $20 \%$ sobre a média total para diagnosticar possíveis mudanças no panorama pluviométrico da região.

Noronha et al. (2016) em estudo utilizaram o IAC para avaliar a intensidade da anomalia do regime de chuva na microbacia de Santa Maria/ Cambiocó- RJ, inferiram que a estação seca se concentrou do mês de junho á agosto. E a estação chuvosa nos meses de novembro, dezembro e janeiro.

Em estudo feito por Chargas e Araújo (2017) por meio do IAC, verificaram os ciclos secos e chuvosos de oito municípios, em uma série histórica de 21 anos, na microrregião do brejo paraibano. Observaram que na região o índice apresentou boa variabilidade entre anos considerados secos e anos considerados úmidos. Destacando o período úmido de fevereiro á agosto como sendo a melhor época para plantio.

Diante do exposto pode-se perceber a importância de estudos ambientais como o monitoramento de eventos meteorológicos eficientes, integrados e de previsão e observação na 
redução e aumento das chuvas ajude no o entendimento da dinâmica dos recursos hídricos e sua espacialização, como geradores de informações sobre o meio ambiente, auxiliem na criação de políticas públicas consistentes para a solução dos problemas ambientais relacionados à escassez hídrica.

O presente trabalho tem como objetivo principal analisar a variabilidade climática da microrregião do Cariri Ocidental Paraibano que é composta por 17 munícipios, através da utilização do Índice de Anomalia de Chuva (IAC) e correlacionar a classificação desse índice com a ocorrência, intensidade e influência do Fenômeno El Niño, observando incialmente se o fenômeno provoca grandes variações nos índices pluviométricos.

\section{Material e métodos}

Localização e Caracterização da Área

A pesquisa foi realizada na microrregião do Cariri Ocidental paraibano, que se localiza no centro do estado da Paraíba. Abrange uma área de 7.012,18 Km² (IBGE, 2019). É composta por 17 municípios, sendo eles: Amparo, Assunção, Camalaú, Congo, Coxixola, Livramento, Monteiro, São João do Tigre, São Sebastião do Umbuzeiro, Serra Branca, Sumé, Taperoá, Zabelê, Ouro Velho, Parari, Prata e São José dos Cordeiros (Figura 1). A população total da área em estudo é de 128.265 habitantes segundo o Instituto Brasileiro de Geografia e Estatística- IBGE (2019).

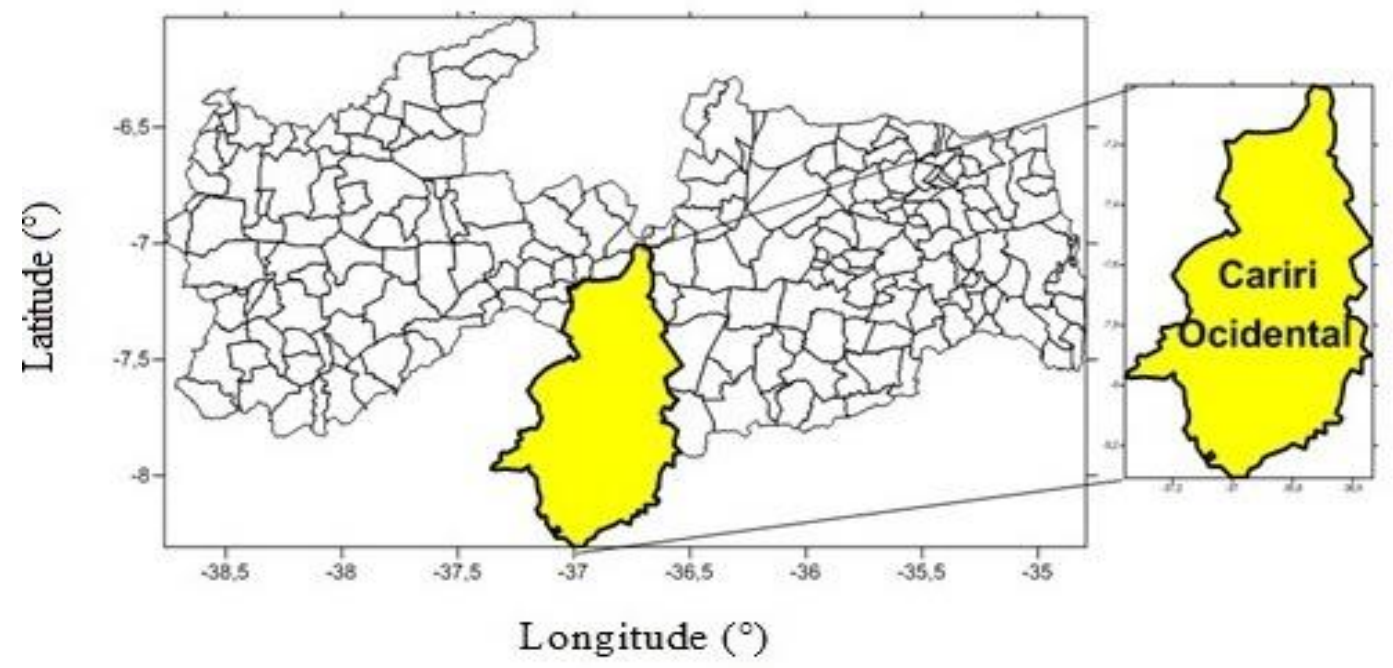

Figura 1. Localização geográfica da microrregião do Cariri Ocidental paraibano.

De acordo com a classificação de Koppen (PDRH-PB, 1996), o clima predominante na região é do tipo Bsh (semiárido quente), precipitações médias anuais muito baixas, em torno de $400 \mathrm{~mm}$, com estação seca que pode atingir até 11 meses (Figura 2). É caracterizado ainda por uma pluviometria que se concentra em 3 a 4 meses do ano, irregularmente distribuídas no tempo e no espaço. As temperaturas médias anuais são relativamente elevadas, $25^{\circ} \mathrm{C}$ a $27^{\circ} \mathrm{C}$, e a insolação média é de 2.800 horas/ano. A umidade relativa do ar é cerca de $50 \%$ e as taxas médias de evaporação são em torno de $2.000 \mathrm{~mm} / \mathrm{ano}$. 


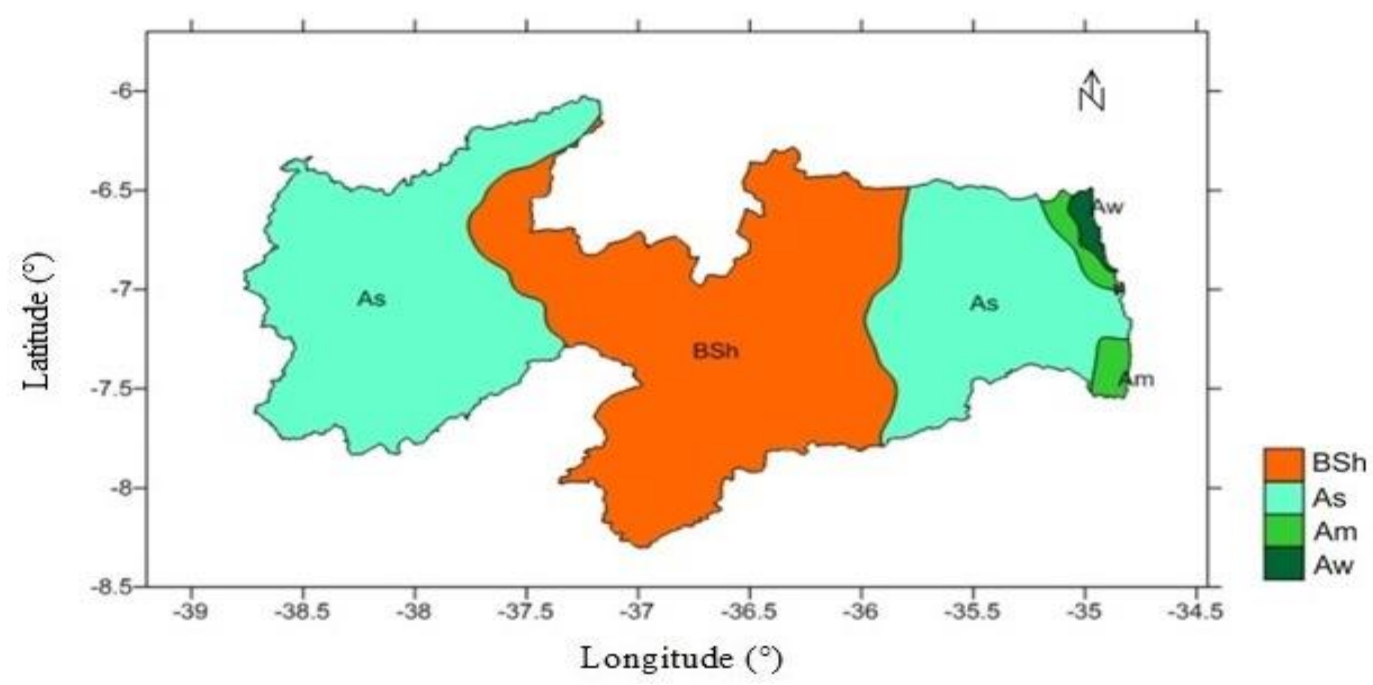

Figura 2. Mapa da classificação climática de Koppen no Estado da Paraíba.

Alves (2009) afirma que esses aspectos climatológicos tornam a caatinga uma formação complexa do ponto de vista espacial, onde sua fisionomia varia bastante dentro do semiárido Nordestino, o que resulta na configuração espacial de comunidade-tipo na caatinga.

A área de domínio do clima semiárido, segundo dados fornecidos pela Universidade Federal de Santa Catarina- UFSC (2011), corresponde à vegetação da Caatinga, isto é, no Sertão, Cariri, Curimataú, Seridó, recobrindo em $65 \%$ o território. Tal vegetação é apresentada por xerófilas, cactáceas, caducifólias e aciculifoliadas. No qual o Cariri é considerada uma vegetação do tipo hiperxerófila (Figura 3), como também áreas mais secas como Seridó e Curimataú. Podem-se citar algumas espécies como as mais comuns: xiquexique (Pilosocereus gounellei), mandacaru (Cereus jamacaru), macambira (Bromelia laciniosa), baraúnas (Schinopsis brasiliensi), aroeira (Schinus terebinthifolius), angico (Anadenanthera colubrina), umbuzeiro (Spondias tuberosa) e o juazeiro (Ziziphus joazeiro).

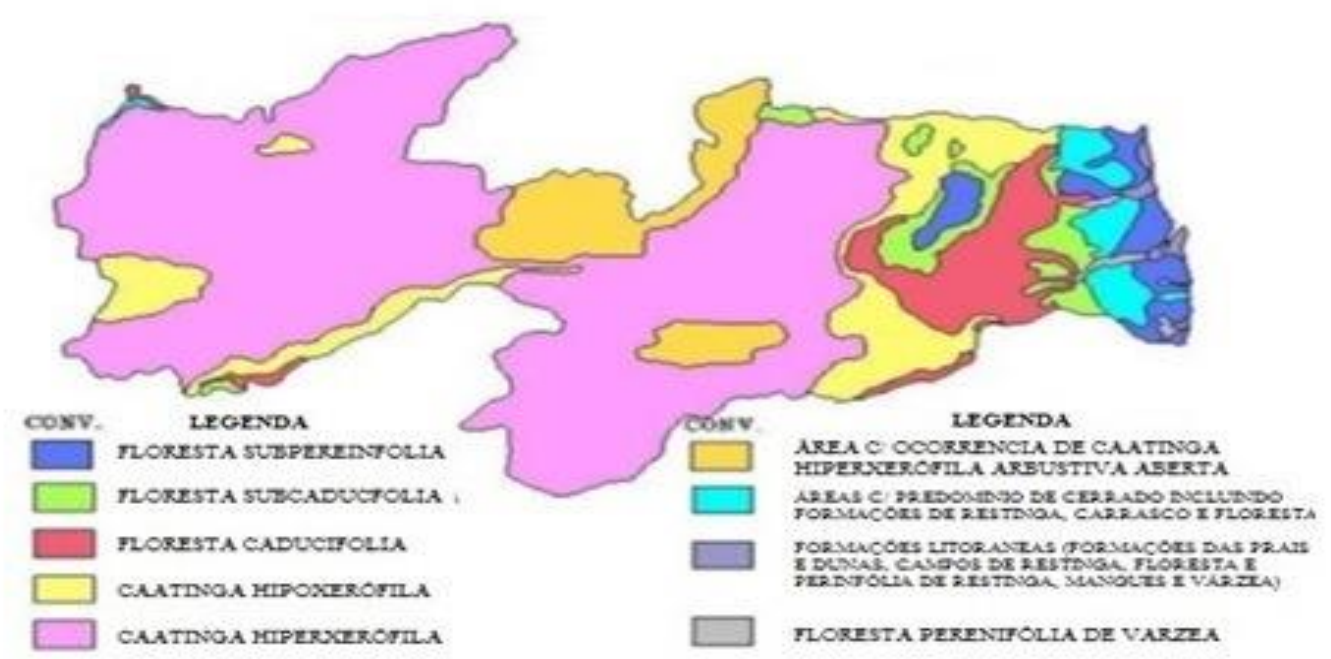

Figura 3. Esboço da vegetação da Paraíba. Fonte: Brasil 1972 - modificado

Esse tipo de caatinga muito frequente caracteriza sempre os setores com aridez edáfica severa, caracterizando os solos como compactos e pedregosos e com grande quantidade de afloramentos rochosos. Sobre os solos rasos e pedregosos recobrem extensas áreas da caatinga, as formações são mais ralas e baixas; tornando a Diniz, R. R. S.; Alencar, M. L. S.; Medeiros, S. A.; Guerra, H. D. C.; Sales, J. C. R vegetação com arbustos pequenos e dispostos em tufos afastados uns dos outros e, às vezes, com cobertura de gramíneas ou de gramíneas e herbáceas entre as Mimosóideas, Cesalpiniaceas, Euforbiáceas (Alves, 2009).

O relevo do Cariri paraibano é tido como residual, que se caracteriza por ser uma elevação 
topográfica que se destaca numa superfície de aplanamento resultante da ação diferenciada da erosão. Apesar de a altitude ser superior a $300 \mathrm{~m}$, prevalece a feição de pediplano de superfície irregular, embutido na superfície de aplainamento do planalto da Borborema. Nesse caso, constitui-se numa área rebaixada pela ação das águas da bacia hidrográfica do rio Paraíba, cortado ocasionalmente por relevos residuais, ora isolados, ora em alinhamentos (ZEE, 2011; Nascimento e Alves, 2008b).

\section{Levantamento dos dados climáticos}

Os dados pluviométricos serão obtidos na Agência Executiva de Gestão das Águas (AESA) para o período de 1999 á 2019. Será tomado como base, além dos dados pluviométricos, dados do fenômeno El Niño, que serão retirados do banco de dados do Centro de Previsão de Tempo e Estudos Climáticos (CPTEC) e do Instituto de Pesquisas Espaciais (INPE).

Os dados pluviométricos foram fornecidos pela AESA serão utilizados para o cálculo do Índice de Anomalia de Chuva (IAC) adaptado por Freitas (2005) e readaptado por Araújo et al. (2009). De forma similar os dados também foram utilizados para a determinação da variabilidade climática espaço-temporal da microrregião do Cariri Ocidental.

Na determinação do grau de severidade dos períodos secos e úmidos será feita por meio do cálculo do IAC, (Freitas, 2004 e 2005), obtido a partir das seguintes equações, que se diferenciam entre anomalias positivas (Eq. 1) e para as anomalias negativas (Eq. 2).

$$
\begin{array}{ll}
I A C=3\left[\frac{(N-\dot{\mathrm{N}})}{(\dot{\mathrm{M}}-\mathrm{N})}\right] & \text { Eq. } 1 \\
\boldsymbol{I A C}=-\mathbf{3}\left[\frac{(\boldsymbol{N}-\dot{\mathrm{N}})}{(\dot{\mathrm{X}}-\dot{\mathrm{N}})}\right] & \text { Eq. } 2
\end{array}
$$

Sendo que,

$\mathrm{N}=$ precipitação anual atual (mm);

$\dot{\mathrm{N}}=$ precipitação média anual da série histórica $(\mathrm{mm})$;

$\dot{\mathrm{M}}=$ média das dez maiores precipitações anual da série histórica $(\mathrm{mm})$;

$\dot{X}=$ média das dez menores precipitações anual da série histórica $(\mathrm{mm})$.

Os dados obtidos são referentes aos dezessete municípios pertencentes à microrregião de Cariri Ocidental, no qual foi escolhida uma série histórica de vinte e um anos. Onde uma das principais dificuldades encontradas nos estudos com relação à chuva, é de se trabalhar com uma série de menor quantidade de falhas possível para que os dados obtidos sejam representativos para a região em estudo. Na série histórica utilizada foi possível verificar segundo dados fornecidos pelo CPTECINPE, os anos que estavam sobre influência do fenômeno El Niño, de acordo com sua intensidade de acordo com a Tabela 1, e os anos de neutralidade foram anos que não apresentaram registros de estarem sob influência do fenômeno.

Tabela 1. Anos de ocorrência e intensidade do evento El Niño entre o período de 2000/17.

\begin{tabular}{cc}
\hline ANOS DE EL NIÑO & INTENSIDADE \\
\hline $\mathbf{1 9 9 9}$ & Forte \\
$2002-2003$ & Moderado \\
$2004-2005$ & Fraco \\
$2006-2007$ & Fraco \\
$2009-2010$ & Fraco \\
2011 & Fraco \\
$\mathbf{2 0 1 2}-\mathbf{2 0 1 3}$ & Forte \\
$\mathbf{2 0 1 5}-\mathbf{2 0 1 6}$ & Forte \\
\hline
\end{tabular}

Fonte: CPTEC, 2019. 
Segundo Santos et al. (2011) uma série ideal tem que se ter no mínimo trinta anos de dados, classificando a série utilizada nesse estudo em uma série do ponto de vista climatológico, considerada bastante curta, no entanto admite-se formular hipóteses sobre tendências de aumento ou redução das chuvas em condições atmosféricas extremas.

Ainda conforme Santos et al. (2011) para a aplicação do IAC é necessário uma adaptação através da qual a quantidade de médias utilizadas para o cálculo do IAC deve ser modificada de maneira a se tornar proporcional à quantidade de dados disponíveis; assim para a quantidade de anos da série histórica utilizada os valores do índice IAC foram obtidos a partir das equações (1) e (2) com as seguintes adaptações:

Quadro 1. Classificações das intensidades das anomalias negativas e positivas de precipitação de acordo com o Índice de Anomalia de Chuva (IAC).

\begin{tabular}{|c|c|}
\hline IAC & CLASSIFICAÇÃO DE INTENSIDADE \\
\hline$\geq 4,00$ & Umidade extremamente alta \\
\hline 3,00 a 3,99 & Umidade alta \\
\hline 2,00 a 2,99 & Umidade moderada \\
\hline 0,00 a 1,99 & Umidade baixa \\
\hline$-1,99$ a 0,00 & Seca suave \\
\hline$-2,00$ a $-2,99$ & Seca moderada \\
\hline$-3,00$ a $-3,99$ & Seca alta \\
\hline$\leq-4,00$ & Seca extremamente alta \\
\hline
\end{tabular}

Fonte: Adaptado de Freitas (2004, 2005); Araújo et al. (2007) .

As incidências de anomalias negativas e positivas de precipitação serão observadas mensalmente e anualmente.

\section{Resultados e discussão}

$\mathrm{Na}$ Figura 4 demonstra a climatologia temporal da precipitação da microrregião do Cariri Ocidental, com as médias mensais de precipitação da microrregião para o período de estudo que foi de aproximadamente $43,7 \mathrm{~mm}$, e que seu período chuvoso tem inicio no mês de janeiro e término no mês de maio, com cinco meses acima da média mensal, sendo o mês de março o mês mais significativo com a média $107,4 \mathrm{~mm}$. O período seco aconteceu entre os meses de junho a
$\mathrm{N}$ = precipitação total medida (anual, mensal, semanal, diária);

$\dot{\mathrm{N}}$ = precipitação total média da série histórica (21 anos) (anual, mensal, semanal, diária);

$\dot{M}=$ média das sete maiores totais precipitações do período analisado;

$\dot{X}=$ média das sete menores totais precipitações do período analisado.

Os valores do índice são ordenados em um esquema de classificação de oito categorias variando de umidade extremamente alta a seca extremamente alta de acordo com Rooy (1965) e adaptada por Freitas (2004 e 2005) e Araújo et al. (2007) como mostra o Quadro 1 abaixo. 


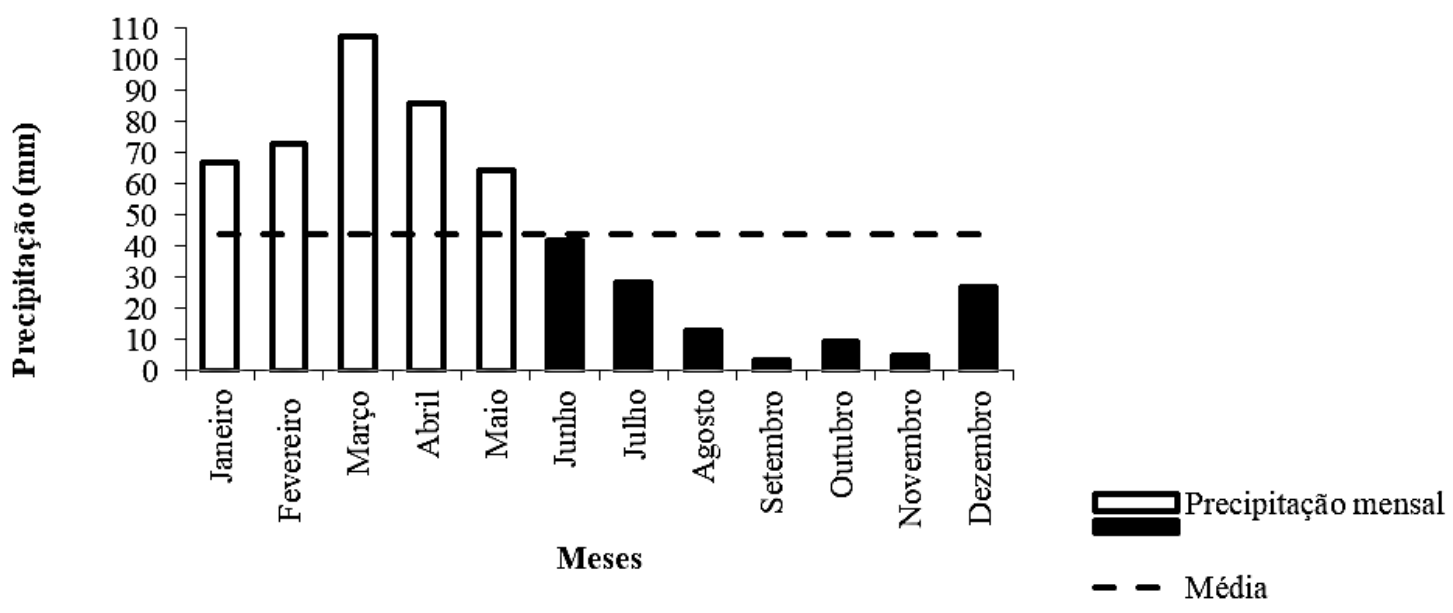

Figura 4. Médias climatológicas da precipitação da microrregião do Cariri Ocidental Paraibano.

Utilizou-se IAC para melhor estimar a variabilidade espacial da precipitação, Figura 5, com intenção de se ter uma melhor identificação na intensidade e duração dos períodos secos e úmidos para série histórica da precipitação utilizada, no qual foram definidos de acordo com a Tabela 1, em dez anos classificados como anos chuvosos. No qual os anos de 2000, 2002, 2005, 2006, 2010, 2019 (Umidade baixa); os anos de 2004, 2008,
2011 (Umidade alta); e o ano de 2009 (Umidade extremamente alta). Ainda de acordo com a classificação da mesma tabela, foram definidos onze anos secos, classificados os anos de 1999, 2001, 2003, 2007, 2014, 2018 (Seca suave); os anos de 2013 e 2015 (Seca moderada); os anos de 2016 e 2017 (Seca alta) e em 2012 (Seca extremamente alta).

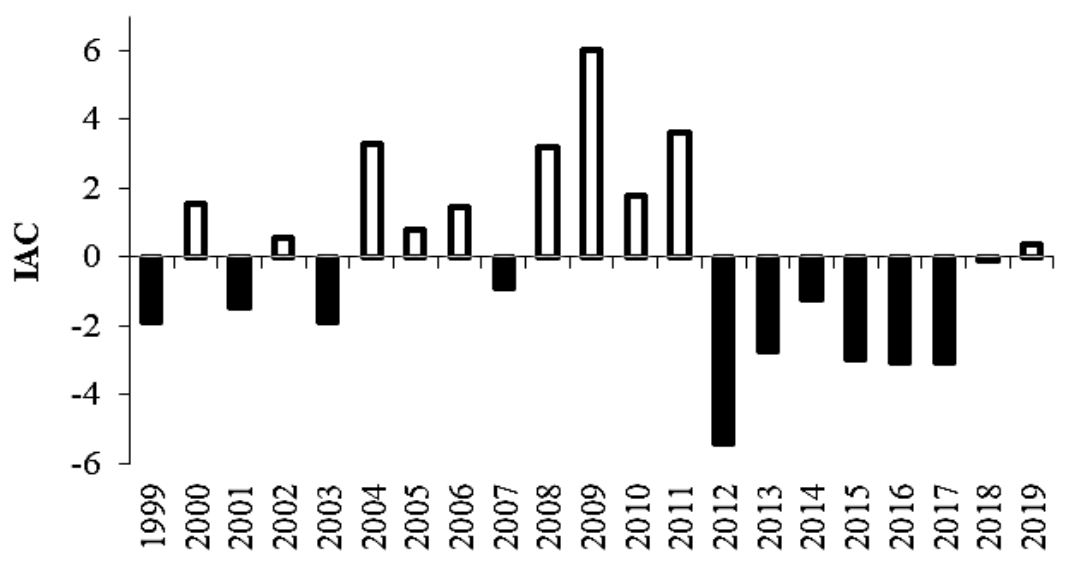

Anos

Figura 5. Índice de Anomalia de Chuva a microrregião do Cariri Ocidental para o período de 1999- 2019.

É importante ressaltar que em períodos úmidos problemas podem ocasionar enchentes nas cidades por falta de infraestrutura, prejuízos na agricultura dentre outras peculiaridades e aos períodos secos podem estar associados a grande dificuldade com a escassez de água, ocasionando a seca, prejuízo também na agricultura, por falta de chuvas e na criação de animal, como outras interações danosas ao meio. Mas, vale também ser ressaltada que em séries pequenas ou grandes de 
precipitação, o importante é a alternância de períodos chuvosos e secos, pois assim se observará um equilíbrio ecológico entre a fauna, flora e o homem, sem prejudicar as atividades e sua dinâmica natural de interação do homem com a natureza (Silva et al. 2018).

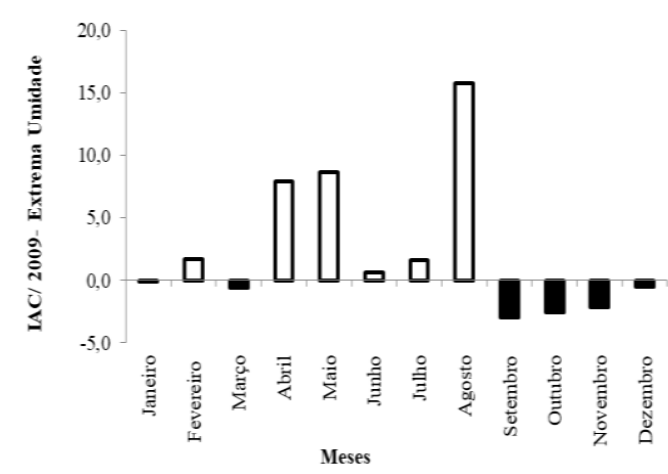

Figura 6. IAC mensal do ano (2009) de extrema umidade da microrregião do Cariri Ocidental.

Dentre os anos úmidos, 2009 classificado como sendo de Umidade extremamente alta, observa-se que, neste ano os meses de janeiro e março não seguem a variabilidade temporal visto na Figura 4, apresentando IAC negativos, e os meses de junho á agosto se apresentaram fora do padrão, onde apresentaram IAC positivo, já os demais seguem a variabilidade climática da estação seca, com chuvas abaixo da média em toda área estudada.

Já entre os anos tidos como Secos, o ano de 2012 (Seca extremamente alta), obteve IAC negativo em todos os meses (Figura 7). Considerando a variabilidade temporal (Figura 4) na qual demonstra que estação chuvosa ocorre de janeiro a maio e a estação seca de junho a dezembro, observa-se que os meses de janeiro a março não seguiu a variabilidade climática dentro da estação chuvosa, ou seja, meses com chuvas abaixo do esperado; já na estação seca, nenhum mês se diferenciou da variabilidade temporal em sua normalidade.

Dentre os anos pertencentes à série de dados utilizada, os anos de 1999, 2012, 2013, 2015 e 2016 de acordo com os dados do CPTEC (Tabela 1), foram considerados anos de El Nino forte. Tal acontecimento apresenta indicação que implique
Para melhor entender o comportamento desse índice, avaliou-se o seu comportamento intra-anualmente, entre o ano tido como de extrema umidade (Figura 6) e o ano de seca extrema (Figura 7), no qual foi identificada também a estação seca e chuvosa dos respectivos anos analisados.

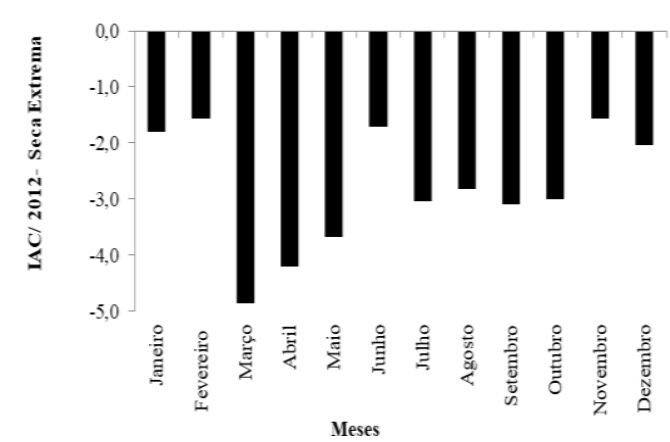

Figura 7. IAC mensal do ano (2012) de seca extrema da microrregião do Cariri Ocidental.

em variações significativas no regime pluviométrico de diferentes regiões do Brasil. A relação entre anomalias positivas $($ IAC > 0) de precipitação e a ocorrência do fenômeno El NiñoOscilação Sul (ENOS) nesta área se dar na correlação na intensidade do El Niño e na classificação do IAC como apresentado no Quadro 1, no qual todos os anos que estavam sobre influencia de El Niño (Forte), foram classificados como anos secos e suas subclassificações.

\section{Análises mensais dos resultados do índice de anomalia de chuvas no cariri ocidental paraibano}

Conforme o resultado observado através da Figura 8 verificou-se que o IAC do mês de janeiro, dos 21 anos, dezesseis anos foram úmidos e cinco anos foram secos, o maior ponto de inflexão, para o mês de janeiro, ocorreu no ano de 2004 e o menor foi em 2011.

Para o mês de fevereiro (Figura 9) foram doze anos úmidos e nove anos secos. O maior ponto de inflexão, para o mês de fevereiro o maior e o menor ponto de inflexão foram respetivamente os anos de 2007 e 2001. 


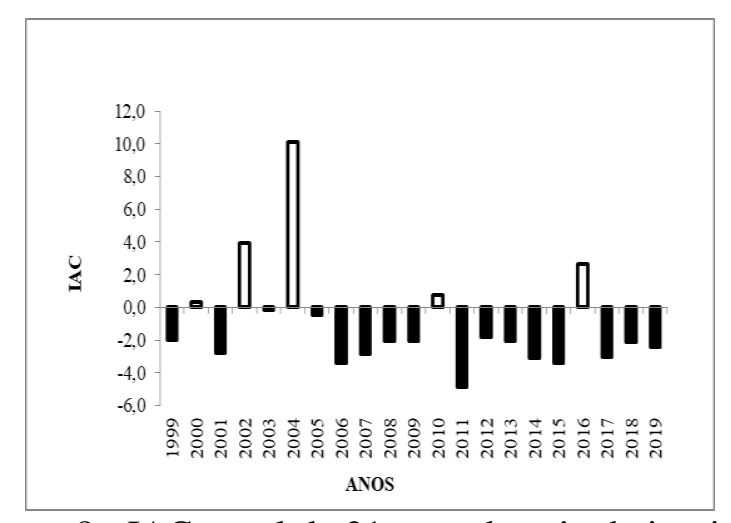

Figura 8. IAC anual de 21 anos do mês de janeiro do Cariri Ocidental paraibano.

Na Figura 10, o IAC do mês de março e abril indicou que houve doze anos úmidos contra os nove anos secos. No mês de março, o maior ponto de inflexão foi obtido no ano de 2008 e o

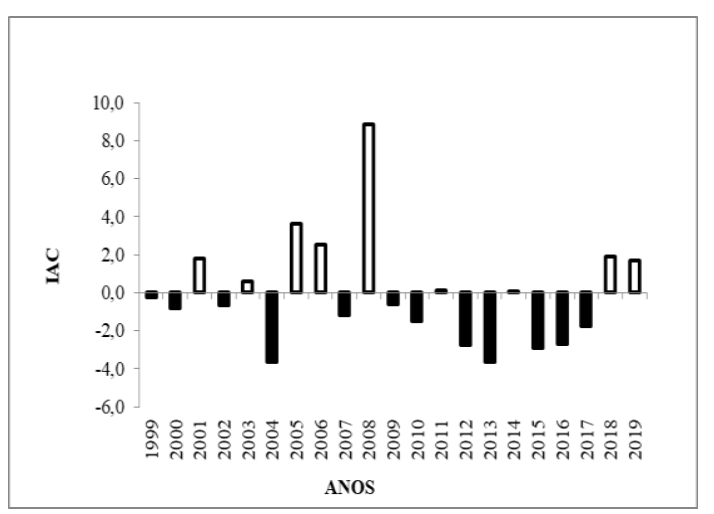

Figura 10. IAC anual de 21 anos do mês de março do Cariri Ocidental paraibano.

Para o IAC da Figura 12, o mês de maio teve treze anos úmidos contra oito anos secos, e, seu maior ponto de inflexão, no período úmido, foi no ano de 2001 e o menor foi no ano de 2007. No período seco, o maior ponto de inflexão foi no ano de 2009. No mês de junho (Figura 13), o IAC,

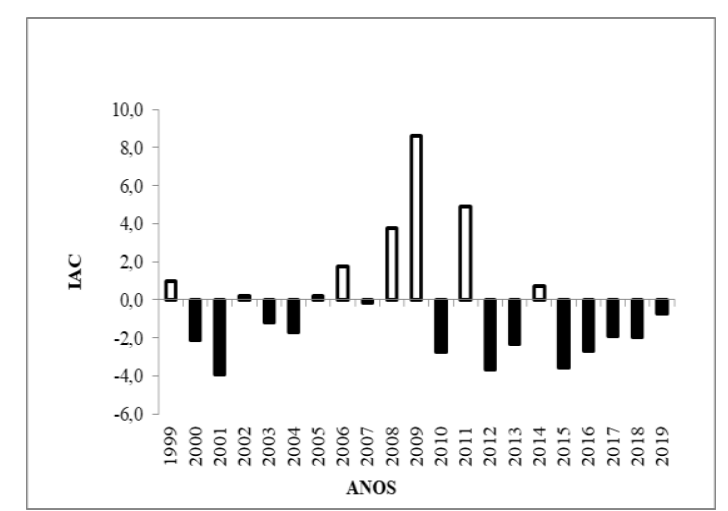

menor em 2004. Para o mês de abril, o maior ponto de inflexão foi no ano de 2009 e o menor no ano de 1999.

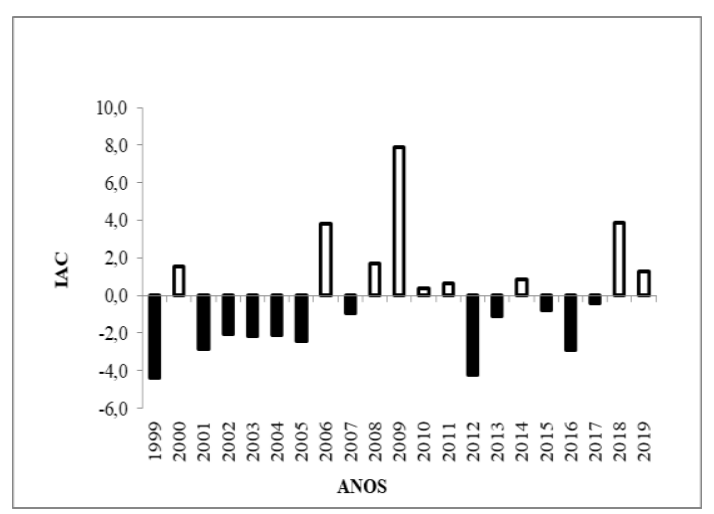

Figura 11. IAC anual de 21 anos do mês de abril do Cariri Ocidental paraibano.

indicou que houve apenas quatorze anos úmidos e sete anos secos. Sendo que o maior ponto de inflexão para o período úmido, desse mês, foi no ano de 2018 e o menor foi no ano de 2000 . No período seco, o maior ponto de inflexão foi em 2010 e o menor foi em 2002.

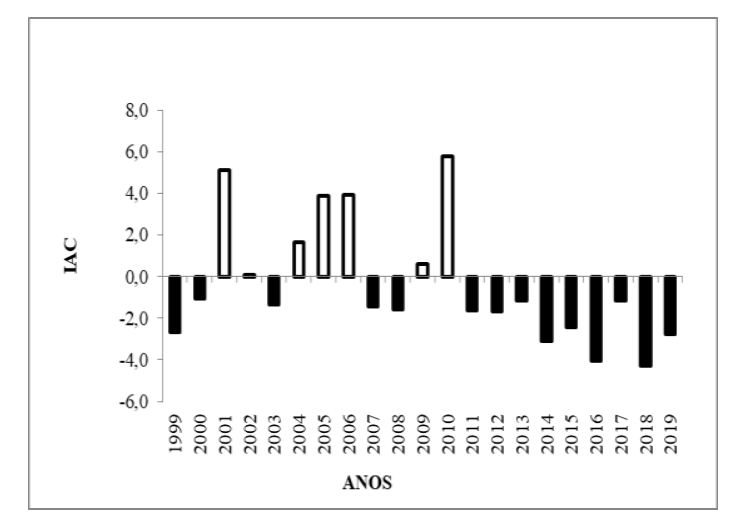


Figura 12. IAC anual de 21 anos do mês de maio do Cariri Ocidental paraibano.

Infere-se na Figura 14 que o mês de julho teve a menor quantidade de anos úmidos (onze), o seu maior ponto de inflexão foi no ano de 2004 e o menor no ano de 2014. Para o mês de agosto (Figura 15), observou-se que foi o mês que mais

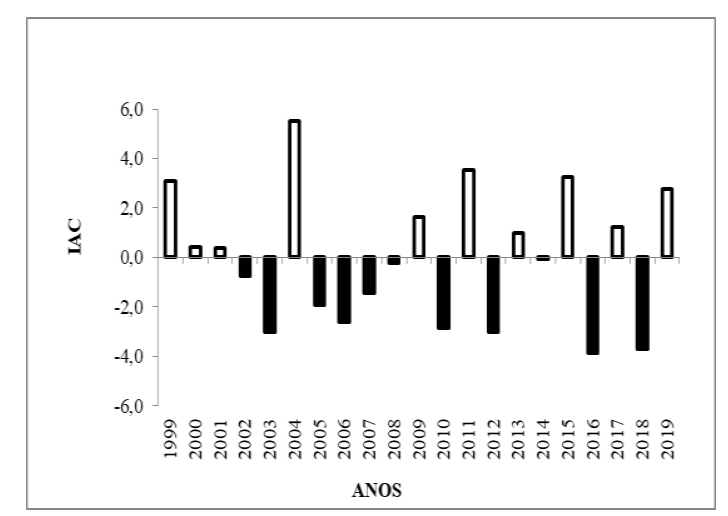

Figura 14. IAC anual de 21 anos do mês de julho do Cariri Ocidental paraibano.

De acordo com a Figura 16, no mês de setembro no período seco, o maior ponto de inflexão foi no ano de 2000 e o menor no ano de 2010. Para o mês de outubro (Figura 17) o total dos

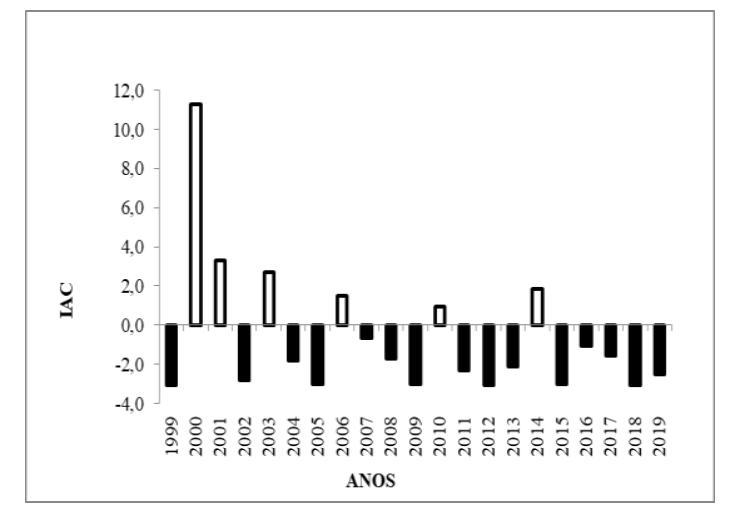

Figura 16. IAC anual de 21 anos do mês de setembro do Cariri Ocidental paraibano.

Os meses de novembro e dezembro, apesar de serem meses nos quais pela variabilidade climatológica serem meses chuvosos, não foram os meses de maior quantidade de anos úmidos. Sendo o mês de Agosto o de maior quantidade de anos úmidos com 17 anos, seguido de Outubro e Janeiro com 16 anos.
Figura 13. IAC anual de 21 anos do mês de junho do Cariri Ocidental paraibano.

apresentou anos úmidos passando para dezessete No período seco, do mês de agosto, o ano de maior ponto de inflexão foi no ano de 2009 e ficando com o menor ponto o ano de 2008 .

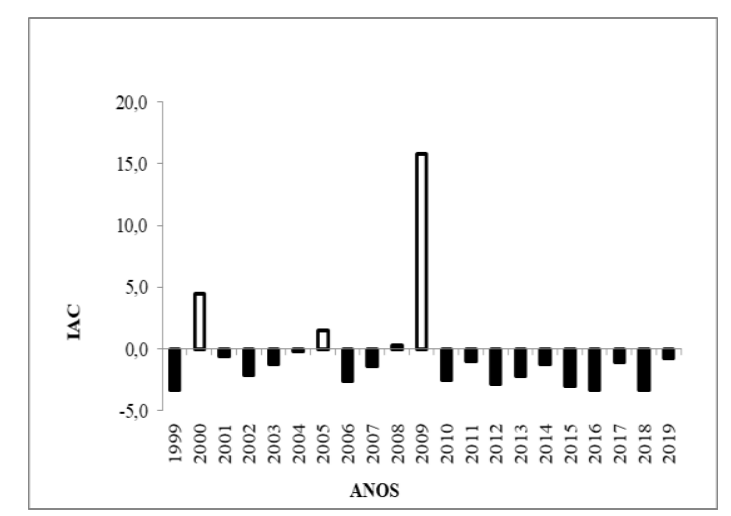

Figura 15. IAC anual de 21 anos do mês de agosto do Cariri Ocidental paraibano.

anos úmidos, passou para 16 anos, e seu maior ponto de inflexão para o período seco, foi no ano de 2010 ficando o menor para o ano de 2011.

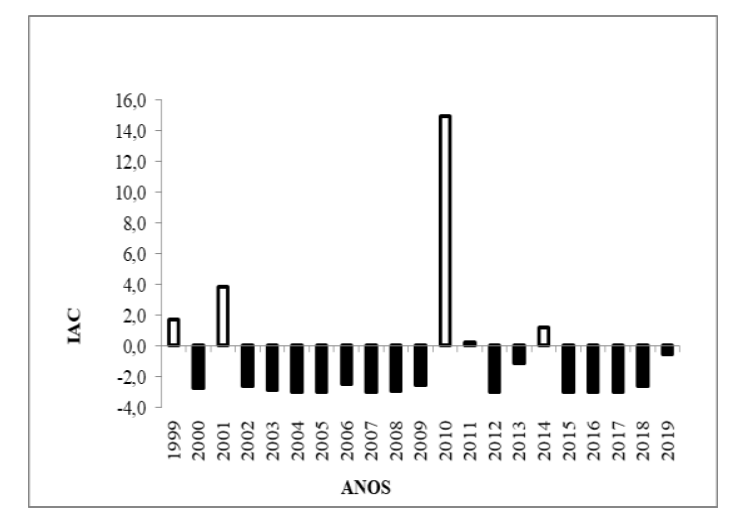

Figura 17. IAC anual de 21 anos do mês de outubro do Cariri Ocidental paraibano.

Em novembro (Figura 18) foram 14 anos úmidos, com maior ponto de inflexão no ano de 2014 e os menores nos anos de 2005, 2010, 2015 e 2016. E dezembro (Figura 19) com 15 anos úmidos, com o maior ponto de inflexão no ano de 2011 e menor no ano de 2018, sendo o mês de 
maior ponto de inflexão, no período seco, no ano de 2000 e o menor no ano de 2015.

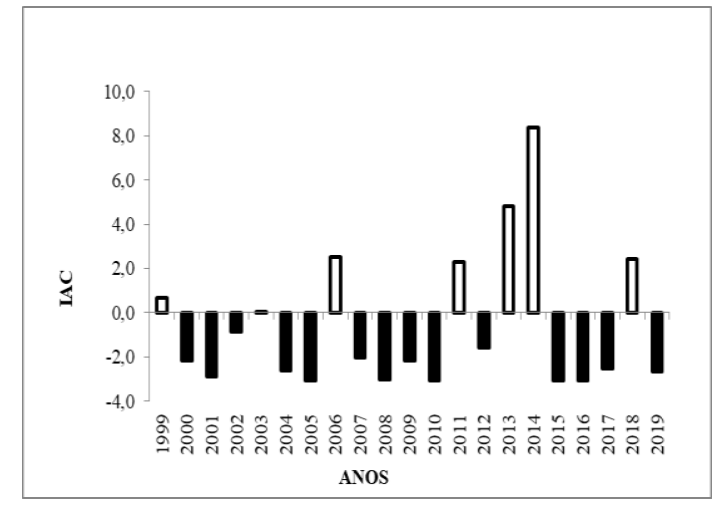

Figura 18. IAC anual de 21 anos do mês de novembro do Cariri Ocidental paraibano.

\section{Conclusões}

Este trabalho possibilitou a analise da variabilidade climática da microrregião do Cariri Ocidental Paraibano, como também a determinação do grau de severidade dos períodos secos e úmidos através o cálculo do Índice de Anomalia de Chuva (IAC).

Com a analise da climatologia temporal da precipitação dos 21 anos (1999 -2019) da microrregião obteve-se médias mensais de precipitação para o período de estudo de aproximadamente $43,7 \mathrm{~mm}$. Destacando ainda o período chuvoso que vai de janeiro ao mês de maio, e o período seco aconteceu entre os meses de junho a dezembro. Constando que para esse período ocorreu mais meses secos do que úmidos na microrregião.

$\mathrm{O}$ cálculo do IAC determinou os períodos de anos secos (10 anos) e úmidos (11 anos), o ano classificado como um período de seca extremamente alta, foi um ano com ocorrência do fenômeno El Nino forte, o que pode ter interferido na pluviometria desse ano, Destacando ainda que todos os anos que estavam sobre influencia de El Niño (Forte), foram classificados como anos secos e suas subclassificações.

Observando o padrão nos pontos de inflexões, os maiores pontos para todos os meses se concentraram nos anos acima do ano de 2000.

O IAC pode ser utilizado como uma ferramenta para o acompanhamento interanual da precipitação pluviométrica de regiões, no qual é possível através dele determinar mudanças em seu regime de chuvas.

Os resultados deste trabalho evidencia a necessidade de mais estudos relacionados ao comportamento climatológico, com ênfase a Diniz, R. R. S.; Alencar, M. L. S.; Medeiros, S. A.; Guerra, H. D. C.; Sales, J. C. R.

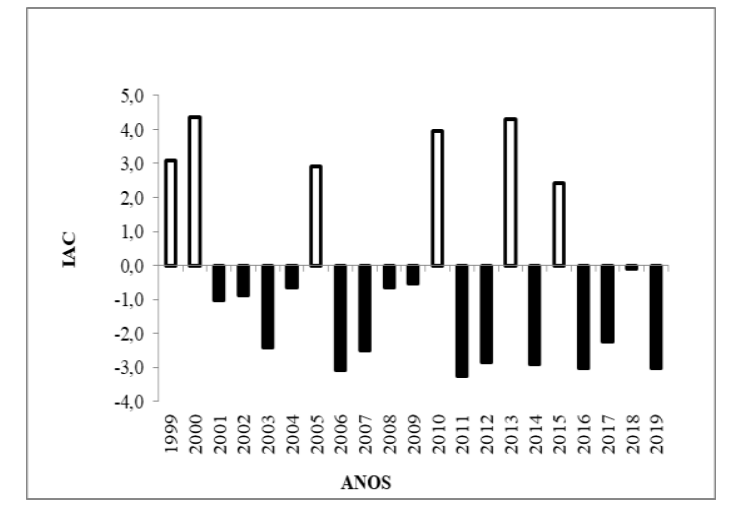

Figura 19. IAC anual de 21 anos do mês de dezembro do Cariri Ocidental paraibano.

precipitação pluviométrica, para corroborar com o planejamento e zoneamento de regiões semiáridas como a da microrregião do Cariri Ocidental para melhorar o aproveitamento e a utilização correta dos recursos hídricos objetivando de se fazer um uso sustentável sem comprometer o regime pluviométrico do estado.

\section{Agradecimentos}

Os autores agradecem o apoio a Coordenação de Aperfeiçoamento de Pessoal de Nível Superior (CAPES) o fomento que viabiliza o desenvolvimento de trabalhos como este.

\section{Referências}

AESA - Agência Executiva de Gestão das Águas do Estado da Paraíba, 2018. Disponível em: http//www.pb.gov.br/aesa. Acesso em: 10 jan. 2020.

Alves, J. J. A. 2009. Caatinga Do Cariri Paraibano. GEONOMOS 17, 19 - 25.

Alves, A.S., Araújo, L.E, 2015. Avaliação climática da precipitação da bacia hidrográfica do rio Camaratuba - PB. Revista Brasileira de Geografia Física [online], 08. Disponível: https://doi.org/10.26848/rbgf.v8.5.p1556-1568. Acesso: 25 jul. 2020.

Araújo, L. E.; Moraes Neto, J. M. De; Sousa, F. De A. S. 2009. Classificação da precipitação e da quadra chuvosa da Bacia do Rio Paraíba utilizando índice de anomalia de chuva (IAC). Ambi-Agua,.4, 93-110.

Araújo, L. E. de.; Silva, D. F da.; Moraes Neto, J. M. de.; Sousa, F. de A. S.de. 2007. Análise da variabilidade espaço- temporal da precipitação na bacia do rio Paraíba usando IAC. Revista de 
Geografia, 24, 47-59. Disponível; http://periodicos.unesc.net/tecnoambiente/articl e/download/4381/pdf. Acesso: 20 jan. 2020.

Bezerra, J. R.A. 2016. A seca no Nordeste brasileiro: uma leitura do Jornal Folha de São Paulo. Temática, ano XII, n. 08.

Chargas Neto, P.; ARAÚJO, Lincoln, E. 2017. Avaliação espaço-temporal da precipitação da microrregião do brejo paraibano. Revista Brasileira de climatologia. Ano 13 - Vol. 21.Disponível:

https://revistas.ufpr.br/revistaabclima/article/vi ew/52904/33651. Acesso: $10 \mathrm{dez} .2019$.

CPTEC- Centro de Previsão de Tempo e Estudos Climáticos. 2016. Monitoramento e previsão do fenômeno El-Niño e La-Niña. Disponível em: www.cptec.inpe.br/enos. Acesso em: 11 de jan. 2020.

Da Silva, D. F.; Araújo, L. E.; Kayano, M. T.; Sousa, F. De A. S. 2009. Avaliação dos impactos da variabilidade climática na distribuição pluviométrica da Bacia do Rio Mundaú através do IAC. In: Simpósio Brasileiro de Desastres Naturais e Tecnológicos, 72. Santos: [S.n.].

Diniz, R. R. S. 2018. Avaliação dos efeitos do El Niño na pluviometria e nos sistemas hídricos do Cariri Ocidental Paraibano com a utilização de geotecnologia. Trabalho de Conclusão de curso / Renata Richelle Santos Diniz. - Sumé - PB: [s.n], Universidade Federal de Campina Grande.

Francisco, P. R. M.; Pereira, F. C.; Brandao, Z. N.; Zonta, J. H.; Santos, D.; Silva, J. V. N. 2015. Mapeamento da aptidão edáfica para fruticultura e zoneamento agropecuário do estado da Paraíba. Revista brasileira de geografia física, 8, 377-390.

Freitas, M. A. S. 2004. A Previsão de secas e a gestão hidroenergética: o caso da Bacia do Rio Parnaíba no nordeste do Brasil. In: Seminário Internacional Sobre Represas y Operación De Embalses. Puerto Iguazú. Anais... Puerto Iguazú: CACIER. 1. 1-1.

Freitas, M. A. S. 2005. Um sistema de suporte a decisão para o monitoramento de secas meteorológicas em regiões Semiáridas. Revista Tecnologia, Fortaleza, 19, 84-95. Disponível: https://periodicos.unifor.br/tec/article/view/117 5/4324. Acesso: 30 mai. 2020.

Gross, J. A.; Cassol, R, 2015. Ocorrências de índices de anomalia de chuva negativos no estado do Rio Grande Do Sul. Rev. Geogr. Acadêmica 9, 21- 33.

IBGE. Instituto Brasileiro de Geografia e Estatística, 2019. Cidades e Estados. Rio de Janeiro: IBGE. Acessível em: < https://www.ibge.gov.br/cidades-eestados.html?view=municipio $>$. Acesso em 05 ago. 2020.

INPE- Instituto Nacional de Pesquisas Espaciais, 2018. Últimas Ocorrências de El Niños. <http://enos.cptec.inpe.br/tab_elnino.shtml>. Acesso em 15 de agosto de 2018.

Nascimento, S.S.; Alves J.J.A, 2008. Ecoclimatologia do Cariri Paraibano. Revista Geográfica Acadêmica. 2 28-41, 2008b. ISSN 1678-7226.

Nóbrega, R. S.; Santiago, G. A. C. F.; Soares, D. B. 2016. Tendência do Controle climático oceânico sob a variabilidade Temporal da Precipitação no Nordeste do Brasil. Revista Brasileira de Climatologia [online], 18, 276292.

Disponível: https://revistas.ufpr.br/revistaabclima/article/vi ew/43657/28724. Acesso: 12 jan. 2019.

Noronha, G. C.; Hora, M. A. G. M.; Silva, L. P, 2016. Análise do Índice de Anomalia de Chuva para a Microbacia de Santa Maria/Cambiocó, RJ. Revista Brasileira de Meteorologia [online], 31, Disponível: http://dx.doi.org/10.1590/0102778620140160. Acesso: 25 jul. 2020.

PDRH-PB. Plano Diretor de Recursos Hídricos do Estado da Paraíba. 1996. João Pessoa/PB: SEMARH/ Governo do Estado da Paraíba. (CDROM).

Santos, E. I.; Alencar, M. L. S. 2015. Efeitos do El Niño nas Variações Pluviométricas e nos Sistemas Hídricos de parte do Cariri Paraibano. XXI Simpósio Brasileiro de Recursos Hídricos. Brasília-DF, Anais.

Santos; P. E.; Correia, M. F.; Aragão; M. R. S.; Silva, F. D. Dos S. 2011. Eventos Extremos de Chuva e Alterações no Regime Hidrológico da Bacia Hidrográfica do Rio São Francisco: Uma Aplicação do Índice Rai (RAINFALL ANOMALY INDEX). Engenharia Ambiental Espírito Santo do Pinhal, 8, 315-330. Disponível:

http://ferramentas.unipinhal.edu.br/engenhariaa mbiental/include/getdoc.php?id=1654\&article $=$ 616\&mode=pdf. Acesso: 11 jan. 2019.

Silva, G. S.; Silva, W. S.; Silva, A. L.; Almeida, N. V.; Araújo, L. E. 2018. Análise da Precipitação da Microrregião do Cariri Oriental Paraibano. REGNE, Vol. 4, $\mathrm{N}^{\mathrm{o}}$ 1. Disponível: https://periodicos.ufrn.br/revistadoregne/article /download/13938/9799/. Acesso: 11 dez. 2019.

Sousa, A.M.L.; Rocha, E.J.P.; Vitorino, M.I.; Souza, P. J. O. P. DE; Botelho, M. N. 2015. Variabilidade espaço- temporal da precipitação na Amazônia durante eventos ENOS. Revista Brasileira de Geografia Física [online], 8, 1324. 
https://periodicos.ufpe.br/revistas/rbgfe/article/ view/233175/27060. Acesso: 30 jun. 2020.

UFSC. Universidade Federal de Santa Catarina, 2011. Centro Universitário de Estudos e Pesquisas sobre Desastres. Atlas brasileiro de desastres naturais 1991 a 2010: volume Paraíba /Centro Universitário de Estudos e Pesquisas sobre Desastres. Florianópolis.
ZEE- Zoneamento Ecológico e Econômico. Governo do Estado da Paraíba. 2011. Os Cariris Paraibanos- Recursos Hídricos, dos Meio Ambiente e da Ciência e Tecnologia. Disponível em: http://paraiba.pb.gov.br/meioambiente-dos-recursos-hidricos-e-da-ciencia-e tecnologia/zee/. Acesso em: 19 dez. 2017. 